\title{
PROPOSTA DE MODELO PARA MELHORIA DE FEEDBACK DOS PROJETOS DE SISTEMAS PREDIAIS HIDRÁULICOS E SANITÁRIOS
}

\section{PROPOSAL OF MODEL TO IMPROVE FEEDBACK ON PROJECTS OF HYDRAULIC AND SANITARY BUILDING SYSTEMS}

\author{
Thaís Marilane Carneiro*E-mail: thaismarilane@gmail.com \\ Daniel Ribeiro Cardoso** E-mail: daniel.br@mac.com \\ José de Paula Barros Neto** E-mail: barrosneto@gercon.ufc.br \\ *Universidade de Fortaleza (Unifor), Fortaleza, CE, Brasil \\ ** Universidade Federal do Ceará (UFC), Fortaleza, CE, Brasil
}

\begin{abstract}
Resumo: A assistência técnica das empresas construtoras, ao acumular informações sobre problemas recorrentes após a ocupação de imóveis, serve como uma fonte de aprendizado para empreendimentos posteriores. Assim sendo, iniciou-se um estudo a partir da análise de arquivos em uma construtora cearense, o que mostrou a presença significativa de reparos ligados aos Sistemas Prediais Hidráulicos e Sanitários (SPHS) em detrimento de outros sistemas construtivos. Posteriormente, a partir de observações, de análise de documentos e de entrevistas em três construtoras locais, realizou-se uma análise do fluxo da informação no setor de assistência técnica das construtoras e a comunicação destas com os escritórios de projetos de SPHS. Com isso, constatou-se que a retroalimentação das informações desses projetos ainda não é uma realidade entre as empresas, mas os projetistas gostariam de receber esse feedback sobre a qualidade de seus produtos. Considerando, a partir do estudo realizado, que as empresas precisam de maior gerenciamento para conseguir reutilizar as informações oriundas do setor de assistência técnica, foi proposto um modelo com uma sequência de passos para a criação de diretrizes de projetos embasadas na coleta organizada de dados nesse setor.
\end{abstract}

Palavras-chave: Projetos. Informação. Sistemas Prediais Hidráulicos e Sanitários. Assistência Técnica. Retroalimentação.

Abstract: Technical assistance from construction companies to gather information regarding recurrent problems after real estate had been occupied, can serve as a source of learning for future projects. This is the introduction to a study which analysed the archives of a construction company from Ceará, Brazil, and showed the existence of significantly higher levels of repairs relating to 'Sistemas Prediais Hidráulicos e Sanitários (SPHS)' (Hydraulic and Sanitary Building Systems) compared to other building systems. Later, after further observing the paperwork and performing interviews with three local construction companies, an analysis was made of the flow of information in the technical service sector of the construction companies and the communication of such to the offices of SPHS projects. It was found that information relating to these projects is not being fed back from other companies, although the designers would like to receive such feedback regarding the quality of their products. The study consequently showed that companies need greater management to be able to reuse the information coming from within the technical service sector, and a model containing a sequence of steps for creating draft guidelines on organised collection of data that sector was proposed.

Keywords: Projects. Information. Hydraulic and Sanitary Building Systems. Technical Assistance. Feedback. 


\section{INTRODUÇÃO}

Problemas com os Sistemas Prediais Hidráulicos e Sanitários (SPHS) constituem uma parcela representativa das reclamações dos usuários de uma edificação, o que pode ser comprovado a partir de estudos como o de Brito (2009), Cupertino e Brandstetter (2012), Fantinatti (2008), Mendonça e Sales (2009) e outros estudos dessa natureza. De fato, no âmbito da tecnologia do ambiente construído, os SPHS vêm aparecendo com relevante frequência em resultados de levantamentos de manifestações patológicas (GNIPPER, 2010). Esse cenário favorece a redução da qualidade do edifício e, consequentemente, diminui a satisfação do usuário final com o produto entregue.

Constata-se, ainda, que problemas relacionados aos SPHS são mais identificados depois da efetiva ocupação do imóvel do que durante o processo de finalização da obra (CHONG; LOW, 2005). Segundo Conceição (2007), os SPHS são os sistemas que mais estão em contato com os moradores ao longo do uso da edificação e seu mau funcionamento gera problemas relacionados ao bem-estar físico e psicológico do ser humano. Mesmo que as patologias frequentes dos SPHS não envolvam sérios riscos à vida ou à saúde dos seus usuários, costumam causar transtornos, aborrecimentos e desconfortos que, em geral, estão associados aos sintomas comuns de suas manifestações, como por exemplo: ruídos nas tubulações, insuficiência de pressão, vazamentos, retornos de gases e mau cheiro nos ambientes, entre outros (ILHA; GNIPPER, 2009).

Por outro lado, os problemas técnicos surgidos após a entrega do produto podem ser vistos como oportunidades para crescer e melhorar continuamente, assim como é usual, por exemplo, em empresas como a Toyota, que buscam aprender a partir de falhas passadas (MORGAN; LIKER, 2008). Assim, a cultura do aprendizado organizacional é reforçada com a aceitação dos erros cometidos e o aperfeiçoamento em troca de experiências internas (SOUZA et al., 2011). Para llha e Gnipper (2009), o mecanismo de retroalimentar a partir dos resultados de investigações patológicas de imóveis entregues é, talvez, o modo mais eficaz de coibir as patologias decorrentes de projetos de SPHS mal elaborados. Desse modo, o setor de assistência técnica das construtoras, pode constituir uma rica fonte de oportunidades de melhorias acerca do desempenho dos novos edifícios a serem construídos (FONG; WONG, 2005).

Contudo, mesmo diante de um considerável acúmulo de conhecimento técnico disponível na área de SPHS obtidos por meio de identificações patológicas, sua aplicação prática constitui, ainda, um obstáculo a ser vencido (GNIPPER, 2010). Assim, a retroalimentação dos dados oriundos do setor de assistência técnica parece não ser uma prática adotada nas construtoras.

Ainda em 1997, Souza (1997) havia identificado que um dos grupos de dificuldades comuns nas construtoras durante o processo de implantação da gestão da qualidade estava relacionado, justamente, à retroalimentação dos sistemas. Nesse grupo de dificuldades, o principal entrave era concernente à falta de ações 
sistematizadas de coleta e análise dos dados como os de Assistência Técnica e Avaliações de Pós-Ocupação (APO) (SOUZA, 1997). Hoje, apesar de toda a agilidade tecnológica, o mesmo problema continua a persistir e os envolvidos na produção têm dificuldade de utilizar informações oriundas da fase de pós-ocupação (JENSEN, 2012; JOHANSSON, 2011).

Trabalhos como o de Aris (2006), Hansen, Damgaard e Haas (2010), Jesnen (2012), Lê e Brønn (2007) e Lundkvist e Meiling (2011) citam a necessidade de retroalimentar as informações de patologias registradas após a ocupação do imóvel. Sobre os SPHS, pode-se ver essa mesma sugestão em estudos brasileiros distribuídos numa linha temporal desde a década de 90, podendo-se citar exemplos como o de Almeida (1994), Amorim (1997), Araújo (2004), Conceição (2007), Gnipper (2010), entre outros. Todavia, esses estudos não chegam a apresentar como seria um modelo mais detalhado dessa retroalimentação.

Tomando por base que as construtoras desejam a redução de solicitações de reparos construtivos e, por consequência, desejam a melhoria da qualidade dos projetos de seus futuros empreendimentos; este trabalho tem por objetivo propor um modelo para sistematização da retroalimentação dos dados coletados no setor de assistência técnica de empresas da construção civil para os escritórios de projeto de SPHS.

\section{RETROALIMENTAÇÃO DE INFORMAÇÕES NO DESENVOLVIMENTO DO PROJETO}

Retroalimentação ou feedback é o retorno da informação que permite a avaliação do cumprimento dos objetivos iniciais. É, na verdade, um pré-requisito para que ocorra a aprendizagem nos processos (GODINHO; MENDES; BARREIROS, 1995).

Constata-se na literatura que existe um limitado número de estudos, principalmente atualizados, sobre reutilização de informações e transferência de conhecimentos de manutenção para a fase de projetos (JENSEN, 2009, 2012).

Observa-se, ainda, que é nessa fase que são tomadas decisões importantes e desenvolvidas formulações com maior repercussão ao longo da vida do edifício (SANCHES E FABRíCIO, 2008). Porém, mesmo considerando o projeto como meio que desempenha a função de definir a forma física do produto para melhor atender às necessidades dos clientes (ULRICH; EPPINGER, 2000); deixa-se, no entanto, em muitas situações, de se considerar nessa fase as verdadeiras necessidades do cliente final.

De acordo com um levantamento feito por Paula et al. (2008), nem sempre os projetistas tomam conhecimento do resultado dos seus projetos após a entrega do imóvel. Segundo Hansen, Damgaard e Haas (2010) além das várias barreiras que dificultam a transmissão do conhecimento adquirido na fase de uso, como por exemplo, barreiras relacionadas com a competência dos funcionários ou com questões sociológicas, as barreiras relacionadas à configuração do processo de 
produção de projeto é um dos fatores que tem afetado bastante a não existência de feedback.

Tzortzopoulos (1999) aponta que para a retroalimentação efetiva e a formação de um ciclo permanente de melhorias dos projetos, além das etapas básicas (que vão do planejamento e concepção do empreendimento ao projeto executivo), o processo de projeto também deveria incorporar as etapas de acompanhamento da execução da obra e do uso da edificação. Esse acréscimo de escopo ao processo de projeto pode vir a minimizar várias deficiências causadas pela falta de conhecimento dos projetistas sobre o que acontece na prática, razão apontada por Johansson (2011) como uma das mais frequentes causas provocadoras de falhas na etapa de projetos.

Dessa forma, é fundamental que a informação sobre defeitos apresentados na produção do edifício causada por erros de projeto seja, em algum momento, compartilhada com os projetistas (JOHANSSON, 2011; PAULA et al., 2008). Aris (2006) e Jesnen (2012) sugerem que as informações sobre lições aprendidas possam tomar a forma de ferramentas, tais como diretrizes ou listas de verificação para os projetistas.

Para que possa haver retroalimentação dos sistemas com esses tipos de informações, todavia, é importante que haja catalogação criteriosa e armazenagem segura (LÊ e BRØNN, 2007). Esta pode ocorrer por meio da existência de banco de dados, permitindo compilações rápidas e triagem de informações relevantes. Möller et al. (2014) ressalta que se deve atenção para que os dados sejam realmente confiáveis e acessíveis, havendo comprometimento e disponibilidade de pessoas chave durante a condução de implantações de sistemas de informação.

Amorim (1997), considerando os projetos de SPHS, propôs uma estrutura de sistemas de informação para a alimentação desses projetos por meio de nove bancos de dados fundamentais e, dentre eles, encontra-se um tópico relativo às informações advindas da fase de pós-ocupação. Com relação a esses bancos de dados, então, pode-se considerar que é preciso saber como coletar os dados para que, de fato, eles venham a ser úteis para o processo de projeto desses sistemas.

Neste sentido, Conceição (2007) e Gnipper (2010) aconselham que deve ser criada uma planilha que facilite e organize as patologias segundo critérios identificadores durante a catalogação in loco dos problemas relativos aos SPHS. Para catalogação das patologias, Conceição (2007) fez uma listagem de reparos nos SPHS orientada por local de ocorrência (cozinha, banheiro, área de serviço e varanda). Já Gnipper (2010), por sua vez, argumentou que, por questão de organização e sequenciamento, o lançamento das anomalias em planilhas deve seguir o critério lógico de tópicos, sendo o agrupamento por subsistema o mais utilizado (água fria, esgoto, por exemplo).

Ao propor uma metodologia sistematizada para supressão de patologias em SPHS, Gnipper (2010) cita ainda que deve existir, após a identificação geral do problema, a identificação da causa que o gerou, a definição da conduta a ser 
tomada para sua solução, a solução propriamente dita do problema e a identificação da fase de origem do problema para posterior prevenção.

Observa-se que as propostas de Conceição (2007) e Gnipper (2010) para coleta de informações complementam-se como um meio bem estruturado para proporcionar a utilização das informações para melhorias em futuros projetos.

Além disso, Souza (1997) recomenda que semestralmente seja elaborado um relatório de assistência técnica, levantando-se em consideração os custos globais da empresa com a mesma, bem como analisando estatisticamente a incidência de falhas por categoria e identificando a causa das falhas (projeto, materiais, execução ou uso). Esse relatório pode ter uma configuração mais didática, como por exemplo, apresentar os resultados a partir de gráficos de Pareto, de forma a priorizar os problemas mais relevantes e ou por meio diagrama de Ishikawa, mostrando as possíveis causas dos problemas (RESENDE; MELHADO; MEDEIROS, 2002). Por fim, tal relatório deve ser divulgado aos departamentos envolvidos, como o de projetos, por exemplo.

Constituindo-se a assistência técnica, portanto, em uma vasta fonte de aprendizado, as informações registradas nesse departamento, fruto do resultado de uma obrigação da empresa em fazer reparos necessários aos produtos entregues, podem, ao mesmo tempo, ser um caminho para retroalimentação e feedback da produção de novos projetos (LUNDKVIST; MEILING, 2011).

\section{METODOLOGIA}

A estratégia de pesquisa utilizada foi o estudo de caso, que deve ser utilizado quando se deseja conhecer profundamente determinado assunto, não se exigindo controle sobre os eventos, e quando 0 foco se encontra em fenômenos contemporâneos inseridos em algum contexto da vida real (YIN, 2005). Além disso, o trabalho é do tipo qualitativo, no qual o problema foi discutido a partir da interpretação dos pesquisadores sobre os dados observados (CRESWELL, 2007). Assim, de forma indutiva, os diferentes dados foram coletados e organizados com o objetivo de construir conceitos e propor melhorias.

Quanto às limitações de um trabalho qualitativo, a presente pesquisa se restringe à proposição de um modelo de retroalimentação dos dados relativos aos SPHS oriundos do setor de assistência técnica para os escritórios de projetos desses sistemas, tendo como embasamento três construtoras cearenses e seus respectivos escritórios de projetos de SPHS.

Quanto ao delineamento do estudo, pode-se conferir na Figura 1 o passo a passo das etapas da pesquisa.

A escolha dos casos para estudo foi baseada em resultados de pesquisas de satisfação realizadas pelo Grupo de Pesquisa e Assessoria em Gerenciamento na Construção Civil da Universidade Federal do Ceará (GERCON/UFC) em Fortaleza/Ce entre os anos de 2007 e 2011. Foram avaliadas as respostas de questionários sobre a satisfação de 23 edifícios residenciais multifamiliares, classe 
média e média alta, de quatro diferentes construtoras locais. Como resultado, constataram-se particulares insatisfações com relação aos SPHS em detrimento de outros sistemas da edificação.

Figura 1 - Delineamento do estudo

\begin{tabular}{|c|c|}
\hline $\begin{array}{c}\text { Preparação para o } \\
\text { estudo }\end{array}$ & $\begin{array}{l}\text { Construtora A - } \\
\text { Caso A }\end{array}$ \\
\hline $\begin{array}{l}\text { - Definição do } \\
\text { problema de } \\
\text { pesquisa na } \\
\text { Bibliografia } \\
\text { - Escolha dos } \\
\text { Casos para estudo }\end{array}$ & $\begin{array}{l}\text { - Análise do fluxo de } \\
\text { informação entre } \\
\text { escritório de } \\
\text { projeto de SPHS e } \\
\text { ConstrutoraA - } \\
\text { Caso A } \\
\text { - Contextualizacão }\end{array}$ \\
\hline $1^{\mathrm{a}}$ ETAPA & $\begin{array}{l}\text { local-serviço de } \\
\text { Assistência Técnica }\end{array}$ \\
\hline $\begin{array}{l}\text { - Análise preliminar } \\
\text { de arquivos }\end{array}$ & $\begin{array}{l}\text { e comunicaçao da } \\
\text { construtora com } \\
\text { escritórios de }\end{array}$ \\
\hline $2^{3}$ ETAPA & $\begin{array}{l}\text { Casos B e C } \\
\text { - Análise da }\end{array}$ \\
\hline $\begin{array}{l}\text { - Análise do Fluxo da } \\
\text { informação no setor } \\
\text { de Assistência } \\
\text { Técnica da }\end{array}$ & $\begin{array}{l}\text { utilidade dos } \\
\text { dados registrados } \\
\text { no setor de } \\
\text { Assistência } \\
\text { Técnica. }\end{array}$ \\
\hline
\end{tabular}

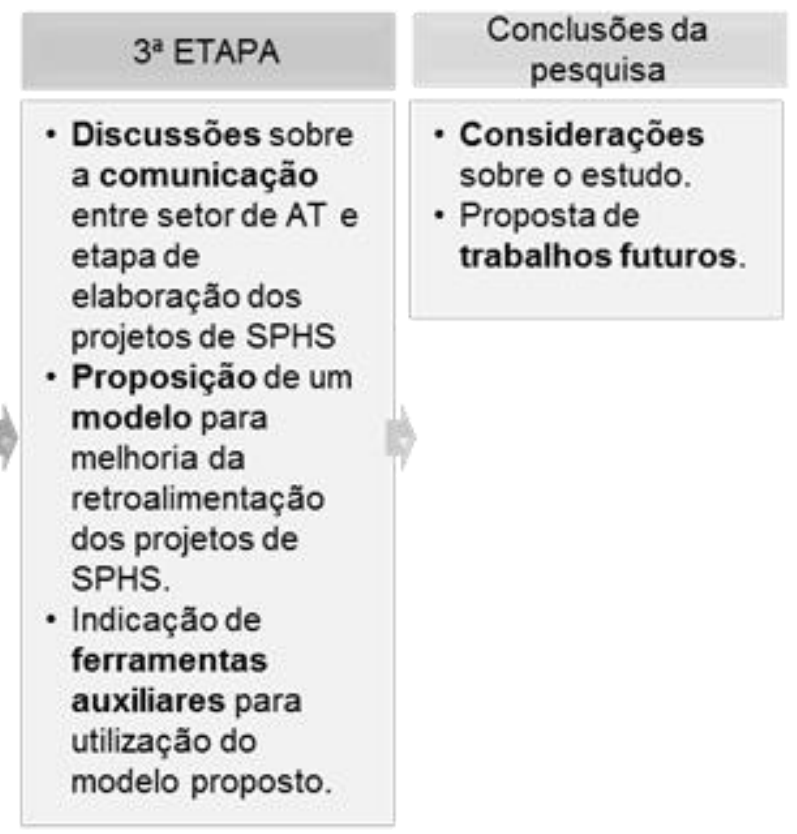

Fonte: autores

Considerando que a presença de insatisfações pode gerar reclamações e solicitações de reparos junto ao setor de assistência técnica das empresas (SINGH, 1988 apud BRITO, 2009), constituiu-se o interesse de saber como essas construtoras utilizavam os conhecimentos adquiridos nesse setor para que as insatisfações não se replicassem em futuros empreendimentos. Assim, foram contatadas as quatro construtoras inicialmente pesquisadas e, de acordo com o acesso e o interesse em participar da pesquisa, foram selecionadas três dessas construtoras para o estudo, aqui nomeadas como Construtoras A, B e C.

As construtoras estudadas são empresas de grande porte, dedicadas à construção de edifícios, principalmente residenciais; estão no mercado há mais de 30 anos e são certificadas pelo Sistema de Gestão da Qualidade - ISO 9001 e Sistema de Gestão da Qualidade em Construção Civil, conforme o PBQP-H, nível "A" (Programa Brasileiro de Qualidade e Produtividade no Habitat). Elas possuem um setor específico destinado aos serviços de pós-entrega da obra, possuindo uma equipe básica exclusiva para os serviços de assistência técnica. Além disso, elas também se assemelham por terceirizarem os serviços de projetos relacionados aos SPHS. Por isso, para cada construtora foi escolhido também um escritório de projetos de SPHS; escritório parceiro com relações comerciais mais frequentes, de forma a verificar os fluxos de informações no processo possível de retroalimentação dos projetos. 
Assim, após o estudo bibliográfico e embasamento teórico inicial, existiu uma análise quantitativa, buscando os problemas mais registrados pelo setor de assistência técnica de umas dessas construtoras. Com essa análise, procurou-se confirmar o que se viu na bibliografia com relação aos índices de registros ligados aos SPHS. A análise teve como base 0 banco de dados da construtora $A$, que possuía 30.307 registros de reparos realizados e distribuídos no período de 2000 a 2011 em 48 empreendimentos, entre residenciais e comerciais (estes, representando apenas dois do total), mas que possuíam similaridade entre as técnicas de produção dos SPHS. Esses dados foram agrupados de acordo com diferentes etapas construtivas, como revestimento/pintura, impermeabilização, piso, entre outras. Com isso, verificou-se a frequência desses grupos ao longo do tempo e se conferiu a quantidade de problemas relacionados aos SPHS em detrimento dos demais grupos categorizados.

Considerando a redução dos índices de reparos como sinais da reutilização das informações do setor de assistência técnica, em um segundo momento, realizaram-se entrevistas junto à mesma construtora (Construtora $A$ ) para certificarse sobre as análises preliminares dos dados fornecidos. Além disso, também se buscou conhecer o perfil dessa empresa quanto aos fluxos de informações dentro do seu setor de assistência técnica.

De modo complementar, também foram realizadas entrevistas junto às outras duas construtoras locais escolhidas, que, mesmo sem disponibilizar seu banco de dados, aceitaram compartilhar sobre seus processos de assistência técnica.

Foram ainda realizadas entrevistas junto aos setores de projetos internos das três construtoras visitadas, bem como em seus respectivos escritórios de projetos de SPHS. No desenvolvimento do estudo foram aplicadas, ao total, dez entrevistas que podem ser melhor entendidas conforme distribuição do Quadro 1.

Quadro 1 - Entrevistas aplicadas aos funcionários das empresas consideradas nesta pesquisa

\begin{tabular}{|l|c|c|c|}
\hline \multicolumn{1}{|c|}{ Entrevista } & $\begin{array}{c}\text { Respondente } \\
\text { Caso A }\end{array}$ & $\begin{array}{c}\text { Respondente } \\
\text { Caso B }\end{array}$ & $\begin{array}{c}\text { Respondente } \\
\text { Caso C C }\end{array}$ \\
\hline $\begin{array}{l}\text { Quanto ao registro e } \\
\text { utilização dos dados } \\
\text { coletados na } \\
\text { Assistência Técnica }\end{array}$ & $\begin{array}{c}\text { Funcionário do Setor de } \\
\text { AT - Construtora A. }\end{array}$ & - & - \\
\hline $\begin{array}{l}\text { Quanto ao serviço de } \\
\text { Assistência Técnica }\end{array}$ & $\begin{array}{c}\text { Gerente de } \\
\text { Obras/Responsável } \\
\text { pelo Setor de AT - } \\
\text { Construtora A. }\end{array}$ & $\begin{array}{c}\text { Responsável pelo Setor } \\
\text { de AT - Construtora B. }\end{array}$ & $\begin{array}{c}\text { Responsável pelo } \\
\text { Setor de AT - } \\
\text { Construtora C. }\end{array}$ \\
\hline $\begin{array}{l}\text { Quanto ao grau de } \\
\text { comunicação entre } \\
\text { construtora e escritório } \\
\text { de projetos dos SPHS }\end{array}$ & $\begin{array}{c}\text { Gerente de } \\
\text { Obras/Responsável } \\
\text { pelo Setor de AT - } \\
\text { Construtora A. }\end{array}$ & $\begin{array}{c}\text { Responsável pelo Setor } \\
\text { de Projetos - } \\
\text { Construtora B. }\end{array}$ & $\begin{array}{c}\text { Responsável pelo } \\
\text { Setor de Projetos - } \\
\text { Construtora C. }\end{array}$ \\
\hline $\begin{array}{l}\text { Quanto à comunicação } \\
\text { com a construtora e à } \\
\text { elaboração dos } \\
\begin{array}{l}\text { Projetos Hidráulicos } \\
\text { Sanitários }\end{array}\end{array}$ & $\begin{array}{c}\text { Responsável pelos } \\
\text { projetos de SPHS do } \\
\text { Escritório A.1. }\end{array}$ & $\begin{array}{c}\text { Responsável pelos } \\
\text { projetos de SPHS do } \\
\text { Escritório B.1. }\end{array}$ & $\begin{array}{c}\text { Responsável pelos } \\
\text { projetos de SPHS do } \\
\text { Escritório C.1. }\end{array}$ \\
\hline
\end{tabular}

Fonte: autores 
Ainda, foram feitas observações não participantes para fins de cruzamento de dados, informações coletadas a partir de documentos cedidos pelas empresas em estudo, consulta a sites e perguntas complementares por e-mail e telefone. Vale ressaltar que na construtora $A$, pela abertura à pesquisa, foram feitas ainda observações mais intensas, chegando-se a ter uma rotina de frequência de acompanhamento no setor de assistência técnica.

Durante entrevista com projetistas, também foram analisados os dados registrados no setor de assistência técnica da construtora $A$, a fim de verificar a utilidade destes dados em futuros projetos de SPHS.

Depois da análise de todas as informações coletadas em campo, foi possível identificar semelhanças e diferenças entre as empresas no que se relaciona tanto ao serviço de assistência técnica das construtoras, quanto à comunicação desses setores com os escritórios de projetos de SPHS. Assim, essas análises permitiram a produção de um modelo de retroalimentação existente nas empresas estudadas, objetivando a visualização de oportunidades de melhorias.

\section{RESULTADOS E DISCUSSÕES}

\subsection{Análise da ocorrência de reparos em SPHS da Construtora A}

$\mathrm{Na}$ Construtora A, foi identificado, em seu registro particular, 263 tipos de problemas que poderiam gerar solicitações de reparo junto ao setor de assistência técnica. Desses reparos cadastrados, identificou-se, entre os anos de 2000 e 2011, a ocorrência de 247 deles, totalizando 30.307 ocorrências de reparos no geral. Esses reparos foram agrupados e distribuídos conforme Gráfico 1.

Gráfico 1 - Pareto dos grupos de solicitações de reparos ocorridos de 2000 a 2011 nos empreendimentos da Construtora A

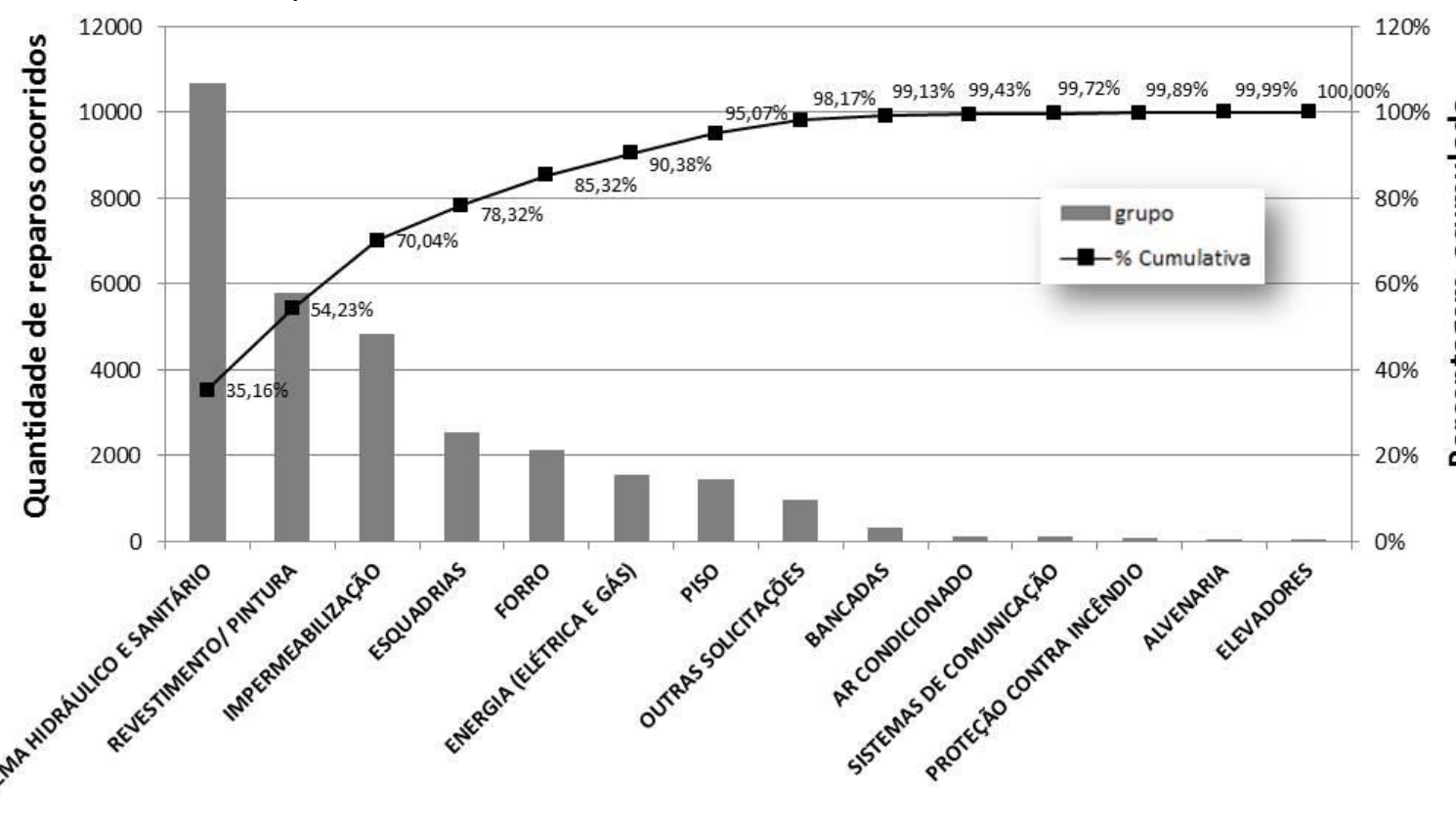

Fonte: autores 
Constata-se que o grupo de Sistemas Hidráulicos e Sanitários foi o que mais se destacou em número de ocorrências (com $35,16 \%$ ), o que aponta uma coerência com os dados já identificados em outros levantamentos de pós-ocupação, conforme citados na introdução deste trabalho.

Todavia, ao longo do período de análise dos dados (2000 a 2011), verificouse uma grande redução dos números de solicitações de clientes ao setor de assistência técnica. No Gráfico 2, os registros de reparos de acordo com os grupos definidos foram distribuídos ao longo dos anos de análises e associados às quantidades de obras atendidas no período, podendo-se verificar as reduções de acordo com os diversos agrupamentos analisados. Vale ressaltar que nos primeiros anos da análise havia mais obras dentro dos cinco anos de garantia, pois se tratava de um período de transição, em que obras antigas ainda estavam sob a responsabilidade da empresa e obras mais novas estavam iniciando o seu período de garantia.

Gráfico 2 - Quantidade de reparos em função da quantidade de obras atendidas no período de 2000 a 2011 - Construtora A

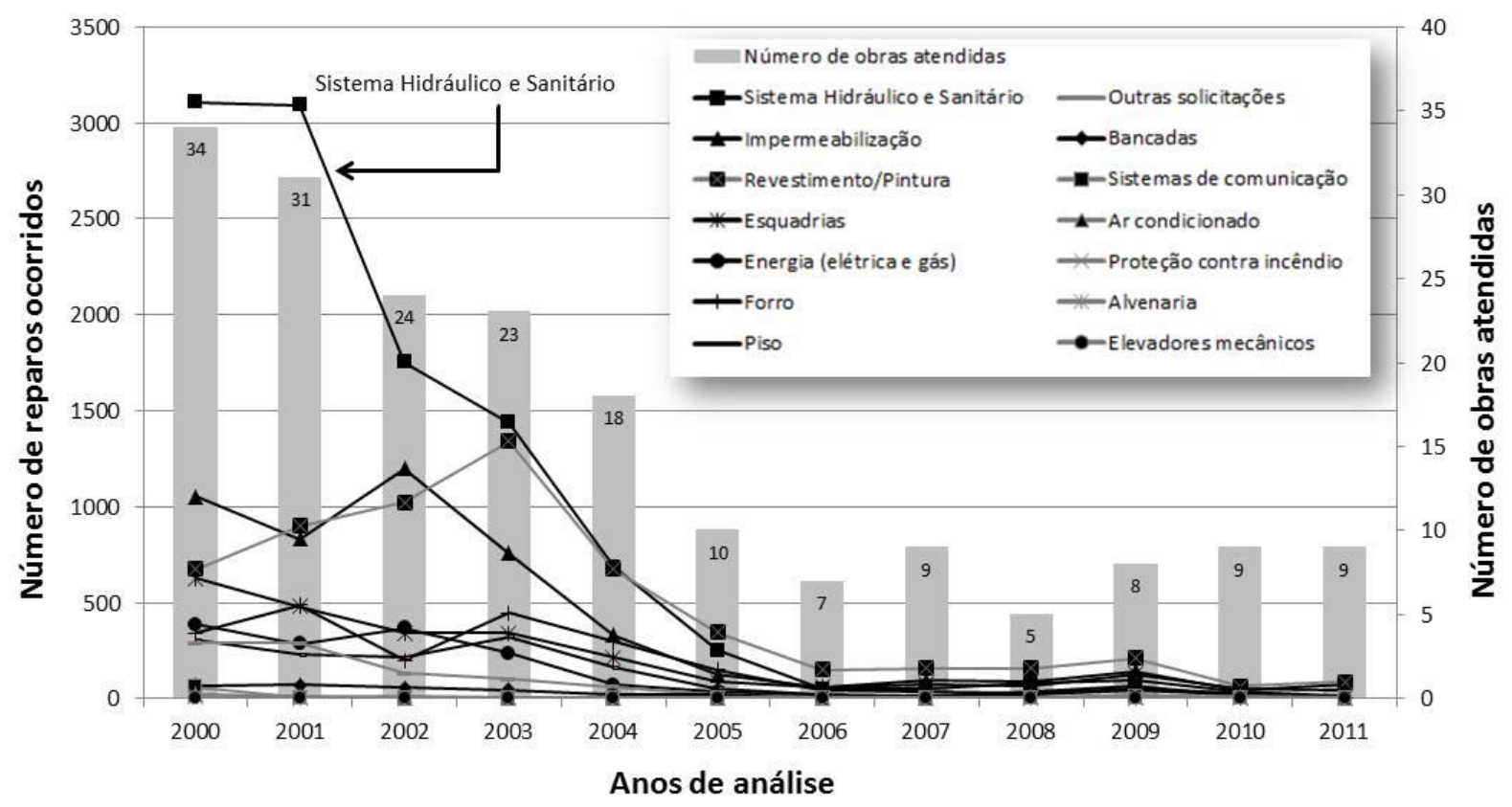

Fonte: autores

Complementarmente, constatou-se que as proporções de reparos por obra atendida também reduziram com o passar dos anos. Por exemplo, no ano de 2000, houve 3.106 reparos ligados aos SPHS distribuídos nas 34 obras atendidas, o que, se fosse fazer uma média, corresponderia a pouco mais de 91 reparos por obra. Com igual raciocínio, no ano seguinte, tem-se quase 100 reparos por obra. Nos anos subsequentes, houve grandes reduções, chegando ao ano de 2011 com uma média de apenas dois problemas ligados aos SPHS por obra atendida.

Nos primeiros cinco anos, os reparos que mais aconteciam eram os relacionados aos SPHS, seguido dos de impermeabilização, revestimento/pintura e 
esquadrias. Estes três últimos se alternavam nas ordens de segundo, terceiro e quarto lugar, mas mantinha-se em primeiro os problemas ligados sempre aos SPHS. A partir de 2005, os SPHS ficaram em segundo lugar no ranking de reparos, passando a ser o alvo das reclamações o item relativo a revestimento/pintura. De 2006 em diante, a ordem de maiores reparos estabeleceu-se como sendo revestimento/pintura, esquadrias ou impermeabilização, impermeabilização ou esquadrias e SPHS. Mas, de um modo geral, essas quantidades e proporções diminuíram consideravelmente em relação aos cinco primeiros anos. No caso dos SPHS, as reduções mais consideráveis foram no tocante aos reparos ligados a rompimento de conexões e a problemas com boia da caixa acoplada das bacias sanitárias.

Diante da análise dos dados expostos, buscou-se, então, saber junto à Construtora A como ela fez para procurar diminuir a ocorrência desses reparos e se as informações do setor de assistência técnica eram utilizadas para evitar reincidências de problemas nas novas construções. Porém, identificou-se que a reutilização de dados não foi um fator decisivo nessa mudança, e sim a redução de prazos de garantia de acordo com cada sistema da edificação. A empresa, a partir do ano de 2005, passou a estipular prazos de garantias diferenciados para cada sistema construtivo. Os SPHS, por exemplo, tinham uma garantia de cinco anos e passaram a ter garantia de apenas um ano para vícios aparentes e ocultos, o que é tolerável dentro dos parâmetros da NBR 15575-1, por exemplo.

Todavia, não sendo descartada a contribuição dos dados arquivados na assistência técnica para a redução dos reparos ligados aos SPHS, foram apresentados três casos de aprendizados em consequência da existência desse setor na Construtora A, a saber: (1) treinamento de mão-de-obra dos operários na fixação de tubos de descida em shafts; (2) melhoria na escolha de materiais a partir da identificação de defeitos com produtos de determinadas marcas, como foi o caso citado sobre válvulas redutoras de pressão; além disso, (3) foi apontada uma melhoria para elaboração dos projetos de SPHS, nesse caso citou-se a inclusão de tubo de ventilação em descidas de águas pluviais como forma de evitar o excesso de pressão no tubo, prevenindo também situações de vazamentos.

Assim, tomando como base que existiram, ainda que de forma simples, alguns aprendizados a partir das informações de reparos, iniciou-se uma análise mais aprofundada sobre o fluxo das informações de pós-ocupação dentro de organizações da construção civil: construtoras e escritórios de projetos.

\subsection{Fluxo de informações em setor de Assistência Técnica das construtoras A, B e C}

Os respondentes das três construtoras abordadas neste trabalho relataram inicialmente a importância das informações do setor de assistência técnica; entretanto, quando questionados, não conseguiam mencionar situações relevantes ocorridas na empresa a partir do aproveitamento dos dados advindos desse setor. A 
Construtora A ainda chegou a relatar alguns casos que indicaram aprendizado quanto aos SPHS a partir dos erros cometidos em obras passadas, mas não possuía uma sistematização de passos entre as operações de retroalimentação para projetos.

Nessas empresas, os dados são normalmente arquivados para fins mais burocráticos, como, por exemplo, em casos de questionamentos por parte do cliente, a empresa consegue esclarecê-lo sobre os reparos realizados, como data, solicitante, operador, local do reparo, etc.

De acordo com as análises feitas no setor de assistência técnica das construtoras estudadas, identificou-se um processo ainda não sistematizado de interpretação e utilização dos dados relativos aos reparos realizados. Assim, podese resumir um procedimento genérico da seguinte forma: (1) são registrados os problemas de construção junto aos clientes e feitas as vistorias para entendimento do problema ocorrido; (2) caso o problema relatado seja de responsabilidade da construtora, o reparo é executado dentro de prazos pré-estabelecidos e (3) após a conclusão do serviço, há o arquivamento da ficha de reparo. Nas três construtoras em estudo, a rotina sistematizada do serviço de assistência técnica é finalizada, portanto, com o arquivamento da ficha de solicitação do reparo, após ser este completamente concluído.

Assim, as empresas preferem não se comprometer nos procedimentos de assistência técnica com passos relativos à retroalimentação de informações oriundas do setor de assistência técnica, apesar de se observar na Construtora A a existência de conferências genéricas aos registros cadastrados.

O que se observou, na verdade, é que, na maioria das vezes, cabe ao supervisor do setor, fazer um apanhado global e, às vezes, subjetivo sobre os reparos mais recorrentes naquele período e, quando necessário, apresentar alguma opinião ao setor técnico da empresa em reuniões periódicas. Nesse momento, quando um problema for recorrente, são discutidas as possíveis causas deste e as alternativas de solução do problema. Às vezes, quando necessário, os problemas são discutidos com empresas subcontratadas e outros participantes envolvidos, como por exemplo, arquitetos, projetistas, empresas terceirizadas e fornecedores, e as soluções podem chegar a ser definidas em um trabalho colaborativo. Quando isso resulta em um processo de mudança técnica ou de construção, as decisões são registradas e divulgadas para o restante da empresa (Figura 2).

Corroborando com o que foi identificado por Fantinatti e Granja (2006), o que se constata é que, apesar de existir um processo padronizado para vários serviços dentro dessas organizações, não existe ainda um registro de sequenciamento e padronização para processos de retroalimentação de informações a partir do setor de assistência técnica. Esses processos até existem, mas parecem acontecer sem muito rigor e padronização. Não existe, por exemplo, uma compilação e uma análise mais aprofundada sobre dados técnicos de reparos registrados, como a descrição da patologia, a causa do problema, a solução adotada e outros. Essas empresas 
chegam até a arquivar o tipo de problema a partir de codificações pré-estabelecidas, mas sem muitos detalhes técnicos, o que não contribui para análises posteriores.

Figura 2 - Esquema de compartilhamento de informações oriundas do Setor de Assistência Técnica das construtoras pesquisadas $(A, B$ e $C)$

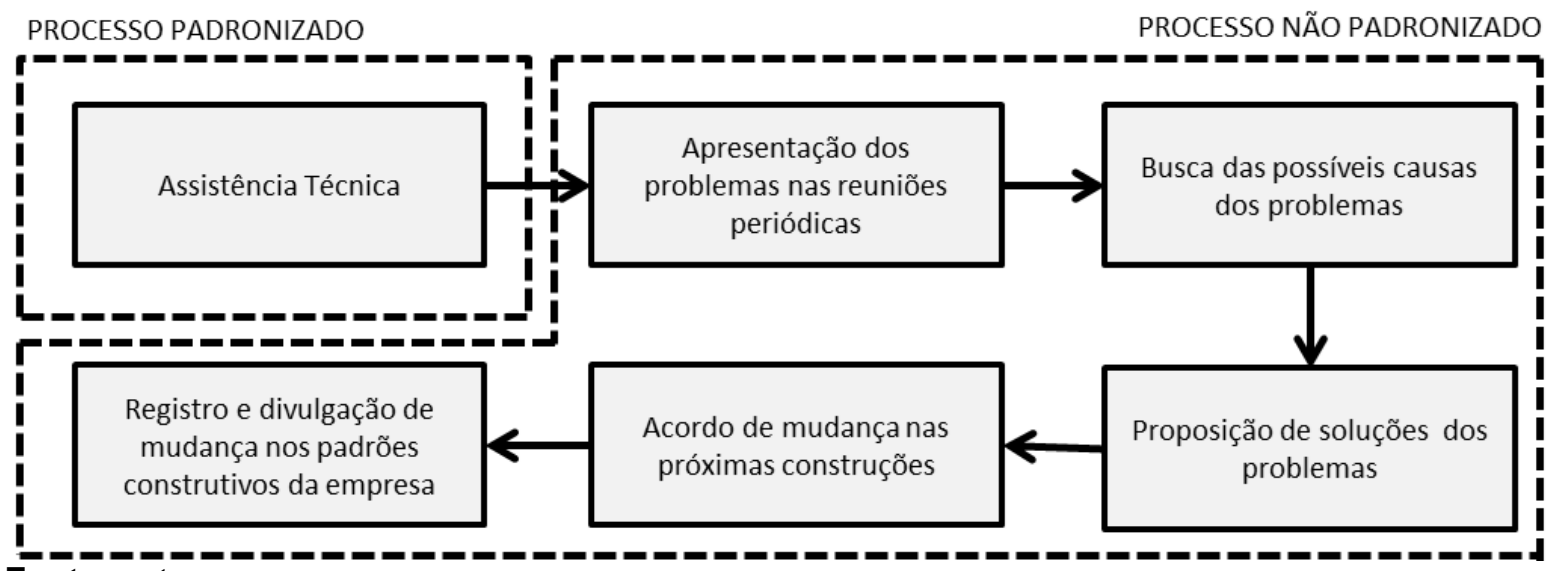

Fonte: autores

\subsection{Fluxo de informações para produção de projetos de SPHS nas compa- nhias estudadas}

De acordo com o levantamento feito junto aos projetistas dos escritórios A.1, B.1 e C.1, existe uma rotina comum de produção dos projetos de SPHS: primeiramente é feito um programa de necessidades, que normalmente se dá a partir de conversa com a construtora. Nos casos do escritório A.1 e C.1, tem-se a utilização de um checklist que auxilia na formalização da coleta de necessidades junto à contratante. Posteriormente, são feitas análises de viabilidade construtivas locais e estudo preliminar da disposição dos equipamentos necessários às instalações desses sistemas. Então, inicia-se a produção do projeto legal e, em seguida, do executivo, sendo este último encaminhado para revisão junto à construtora. Com os ajustes e compatibilizações feitos pela empresa contratante, o projeto volta ao escritório para alterações necessárias, até se obter, finalmente, o projeto executivo liberado para a obra. Desse modo, então, são finalizados os serviços relativos aos SPHS. Apenas na construtora A existe o retorno de informações relativas às alterações ocorridas durante a execução do projeto, de modo que seja produzido o projeto as built dos SPHS pelo Escritório A.1.

A Construtora B afirmou que as atualizações dos projetos são feitas por meio da própria empresa. No caso dos SPHS, que são serviços terceirizados por esta construtora, as empresas terceirizadas ficam responsáveis pelas atualizações finais dos referidos projetos. Confirmando os relatos, o Escritório B.1 afirmou que, depois de concluído o projeto executivo e não tendo sido contratada a produção do projeto as built, não mantém, de fato, nenhum contato para atualizações em projetos passados, a não ser para tirar alguma dúvida e melhorar detalhes executivos se forem requisitados. Já o Escritório C.1 afirmou não ser comum a produção de projetos as built por eles, sendo apenas requisitados para alguns esclarecimentos 
básicos em relação ao projeto executivo entregue. $\mathrm{Na}$ Figura 3, pode-se acompanhar uma sequência comum de passos para produção dos projetos de SPHS.

Considera-se, além da produção dos projetos as built, o retorno de informações do setor de assistência técnica como uma boa forma de possibilitar um feedback aos projetistas sobre a qualidade de suas produções. Todavia, em relação às alterações que acontecem após a ocupação dos imóveis, os projetistas declararam também não tomarem conhecimento algum sobre essas alterações, pelo menos não de maneira formal e sistematizada. Por exemplo, os responsáveis pelos escritórios B.1 e C.1 não sabem se estão usando alguma informação que se tornou padrão na empresa por motivos de patologias detectadas durante assistência técnica. Assim, portanto, em nenhum dos casos estudados faz parte da rotina do desenvolvimento dos projetos de SPHS a conferência de dados de problemas passados.

De acordo com o levantamento feito, os projetistas consideram que o recebimento de um feedback das reclamações dos clientes seria de fundamental importância e que isso poderia se dar por meio de reuniões junto à construtora. Durante entrevista, porém, alguns dos projetistas relataram perceber que as construtoras não demonstram interesse em repassar informações sobre os problemas registrados no setor de assistência técnica.

Figura 3 - Fluxo do processo de projeto dos SPHS dos escritórios estudados na pesquisa.

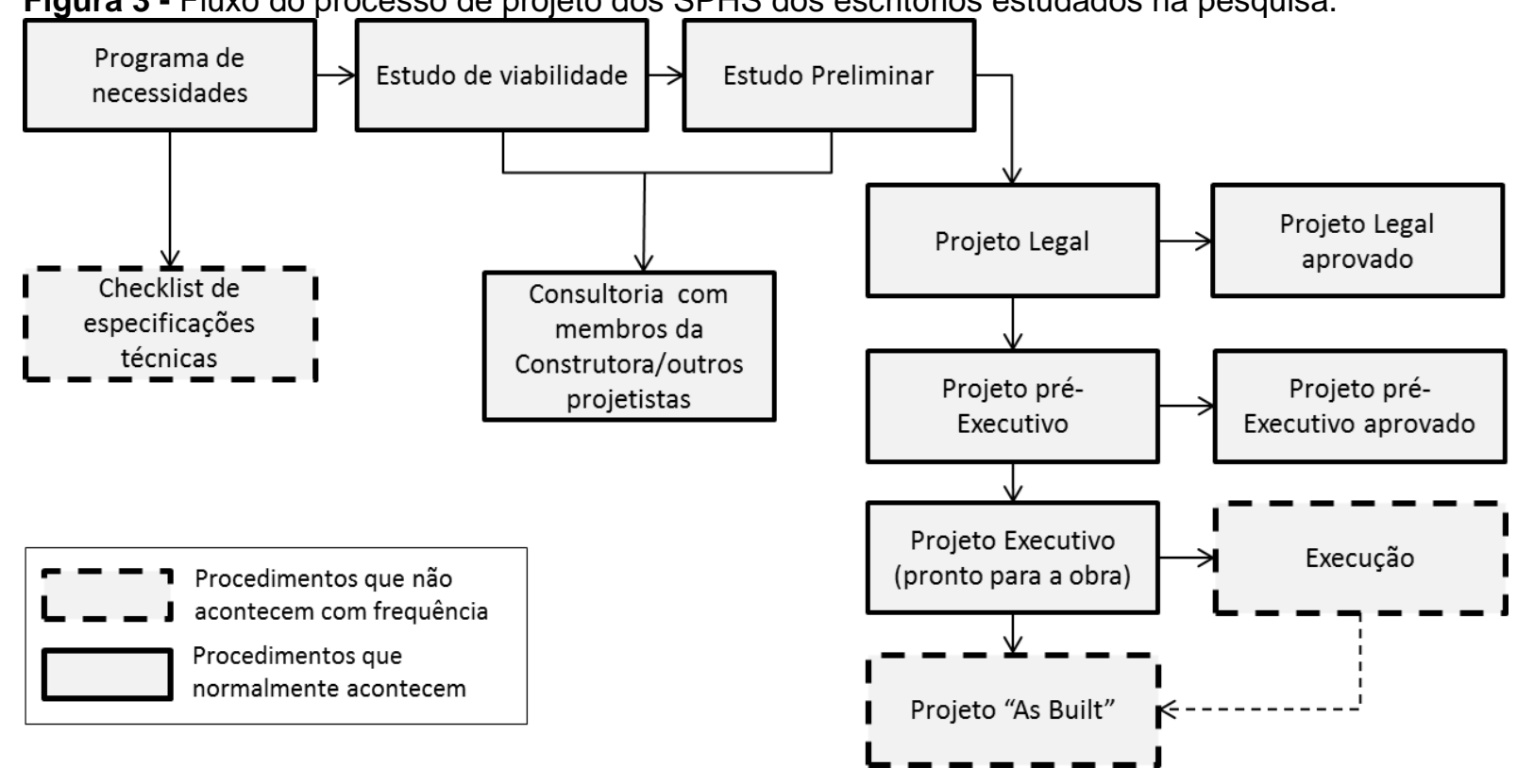

Fonte: autores

Observou-se que as construtoras aqui mencionadas têm conhecimento da fonte de aprendizado que o setor de assistência técnica configura e possuem, ao mesmo tempo, desejo pela melhoria dos projetos de suas novas construções. Por outro lado, contudo, os escritórios de projetos de SPHS contratados por estas não 
são informados da qualidade e desempenho dos sistemas por eles projetados, principalmente, no tocante à fase de uso e operação desses sistemas.

Com isso, foi feita uma avaliação paralela junto aos projetistas para constar se as informações de reparos cadastradas em um atuante setor de assistência técnica seriam proveitosas para eles. Os respondentes dos três escritórios aqui estudados consideraram que as informações apresentadas seriam muito genéricas para auxiliá-los em qualquer processo de melhoria. Sugeriram que esses dados deveriam vir associados a descrições das causas e dos procedimentos de reparos usados para a solução do problema.

De fato, ratifica-se a avaliação dos projetistas com base em um exemplo constatado durante a pesquisa em campo: após ter havido uma solicitação de reparo de uma caixa de passagem de água pluvial em um dos edifícios recém-entregue pela Construtora $\mathrm{A}$, o funcionário do setor de assistência técnica foi até o local e analisou a responsabilidade da empresa em relação ao caso. Diante da verificação de desmoronamento da referida caixa, o problema foi registrado e repassado a um operário do setor para a realização do devido reparo.

No momento de registrar o problema no sistema interno da empresa, por ausência de outra codificação pré-existente compatível e disponível no programa utilizado, a ocorrência foi registrada em um código que mencionava o reparo como sendo problema de piso. Todavia, o que se observou foi que o problema havia acontecido porque a caixa de passagem de água pluvial se encontrava em um local de trânsito frequente: a rampa de acesso ao estacionamento do prédio.

Caso essa informação chegasse aos projetistas simplesmente como a codificação genérica do problema, seria muito pouco provável haver um entendimento da real situação ocorrida e poderia continuar havendo em novos projetos a disposição de caixas de passagem em locais que já se mostraram inadequados.

Desse modo, percebe-se a importância da existência de um sistema que possibilite maiores detalhamentos durante o registro dos dados no setor de assistência técnica, bem como sistemas de processamento e disseminação eficientes de informações para todos os envolvidos na produção dos novos empreendimentos.

\subsection{Proposição de modelo para retroalimentação de informações em projetos de SPHS}

No presente modelo, apresentam-se fluxos de informações de processos que são comuns de ocorrerem em construtoras e em escritórios de projetos de SPHS para a produção de novos empreendimentos, abrangendo o período desde o momento da contratação dos projetos até a fase de assistência técnica pela construtora.

Desse modo, algumas melhorias possíveis de serem implementadas na comunicação entre os projetistas de SPHS e as empresas de construção civil foram 
inseridas nesse processo. Os pontos que se mostraram fracos ou inexistentes quanto à retroalimentação para os escritórios de projetos foram aqui preenchidos com soluções alternativas, considerando-se a revisão bibliográfica feita para a pesquisa $e$ as abordagens de boas práticas e oportunidades de melhorias observadas nos casos estudados.

A seguir, descrevem-se passos, identificados nos casos estudados, que foram considerados como boas práticas a serem realçadas no modelo proposto:

a) Alguns escritórios de projetos de SPHS, a fim de uma formalidade no estabelecimento das características relacionadas aos novos projetos, possuem uma ficha de especificações técnicas para preenchimento por parte da contratante, de forma que haja um repasse formal das técnicas construtivas a serem utilizadas;

b) As construtoras, ao receberem os projetos de SPHS, verificam o cumprimento dos critérios construtivos estabelecidos no ato do contrato, bem como verificam a compatibilidade desses projetos com os demais, como arquitetura e estrutura, por exemplo;

c) Os projetos executivos só são liberados para a obra conforme tenha havido adaptações necessárias solicitadas após revisão da construtora.

Por outro lado, foram também identificadas, nos casos estudados, algumas oportunidades de mudanças para melhorias futuras, como por exemplo:

a) Quando há produção dos projetos as built, comumente esta é feita pelos funcionários da própria construtora, que estão envolvidos na produção do empreendimento. Não existe, todavia, participação dos projetistas envolvidos inicialmente;

b) Não existe um processo de investigação mais aprofundado sobre as causas dos problemas registrados no setor de assistência técnica, nem registros de como foi dada a solução pela construtora;

c) Os registros no setor de assistência técnica são feitos em banco de dados eletrônico destinado a esse fim; contudo, não existe um critério de categorização por etapas construtivas, o que desfavorece futuras análises;

d) Quando os dados de manutenção são extraídos para alguma análise, a averiguação restringe-se à visualização dos números de reparos por empreendimento dentro de um determinado intervalo de tempo. Como esses dados não estão associados a suas causas e soluções, as informações do setor de assistência técnica servem mais como um informativo, que irão refletir melhorias apenas quando há o auxílio e suposições de funcionários que têm o conhecimento dos processos que estão sendo feitos nas obras;

e) Ainda, os reparos de manutenção não são apresentados e discutidos com os profissionais que projetaram esses sistemas.

Quanto à bibliografia, foram consideradas a ideia abordada por Tzortzopoulos (1999) sobre a fase de pós-ocupação fazer parte do processo de projeto; a abordagem proposta por Amorim (1997) sobre a existência de banco de dados de 
pós-ocupação para auxílio dos projetistas no desenvolvimento de seus trabalhos; a abordagem proposta por Gnipper (2010) sobre método sistematizado para supressão de patologias dos SPHS em levantamentos de campo; a abordagem proposta por Conceição (2007) e Gnipper (2010) sobre a organização lógica das patologias dos SPHS, a indicação de Souza (1997) e Resende, Melhado e Medeiros (2002) sobre produção de relatórios gráficos contendo os dados dos serviços de pós-ocupação e a fundamentação em Aris (2006) e Jensen (2012) sobre indicações de lições aprendidas na produção de novos projetos.

Desse modo, a presente proposta tem como base as descrições já feitas ao longo da pesquisa sobre os casos estudados e a revisão bibliográfica, podendo servir, com os ajustes necessários, como um modelo para empresas construtoras reutilizarem sistematicamente os dados relativos aos SPHS cadastrados em seu setor de assistência técnica. Assim, também há possibilidade de os projetistas da referida área de conhecimento serem periodicamente informados sobre os principais problemas ligados aos sistemas com os quais trabalham, de modo a contribuírem com soluções de projeto que agreguem valor à melhoria das futuras construções.

Portanto, conforme descrição abaixo e ilustração representada na Figura 4, é apresentado um modelo de gestão com a sistematização de passos visando a retroalimentação de informações aos projetos de SPHS:

1. Aponta-se que as construtoras, no ato do contrato, repassem formalmente para os projetistas seus critérios construtivos relacionados aos SPHS, de modo a facilitar a produção desses projetos e a reduzir as dúvidas no seu detalhamento;

2. O projeto executivo deve ser conferido pela construtora para compatibilizações entre projetos e verificações de padrões construtivos adotados e, posteriormente, deve ser repassado aos escritórios de projetos para as adaptações necessárias;

3. O projeto executivo final deve ser repassado para a obra com prévia verificação por parte do corpo técnico de projetistas da construtora;

4. Com eventuais modificações na execução, a obra deve registrar as alterações de projeto, de forma que o escritório de SPHS possa fazer suas avaliações e validar ou não as alterações, elaborando ao final da construção o projeto as built,

5. Conforme modificações registradas na obra, o projeto as built deve ser entregue à construtora e aos terceirizados. O setor de assistência técnica deve arquivar uma cópia do projeto para possíveis conferências; 
Figura 4- Ilustração de modelo para melhoria da retroalimentação de informações entre construtoras e respectivos escritórios de projetos de SPHS

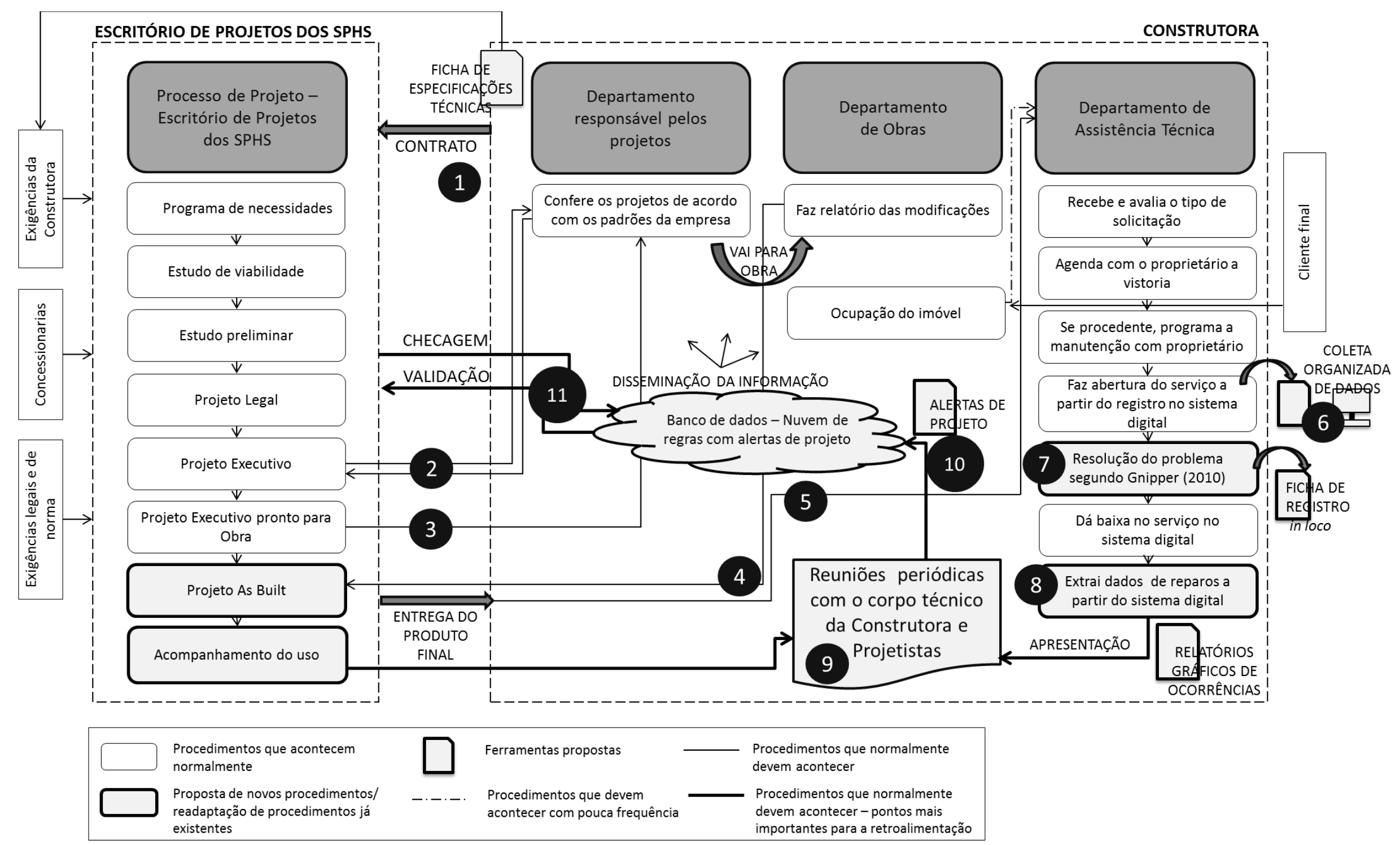

Fonte: autores 
6. Registros de reparos relativos a esses projetos devem ser arquivados pelo setor de assistência técnica em um sistema destinado a esse fim, de modo a se tornarem dados organizados para sua posterior utilização. Na Figura 5, mostra-se uma proposta de planilha sistematizada para registro de reparos de manutenção. A ideia é que os registros possam ser efetuados de maneira que possibilite a escolha da característica desejada do reparo e considere, ainda, os diversos empreendimentos atendidos e as várias datas de registros.

Figura 5 - Proposta de planilha para sistematização de registro dos reparos no Setor de Assistência Técnica com vistas a retroalimentação

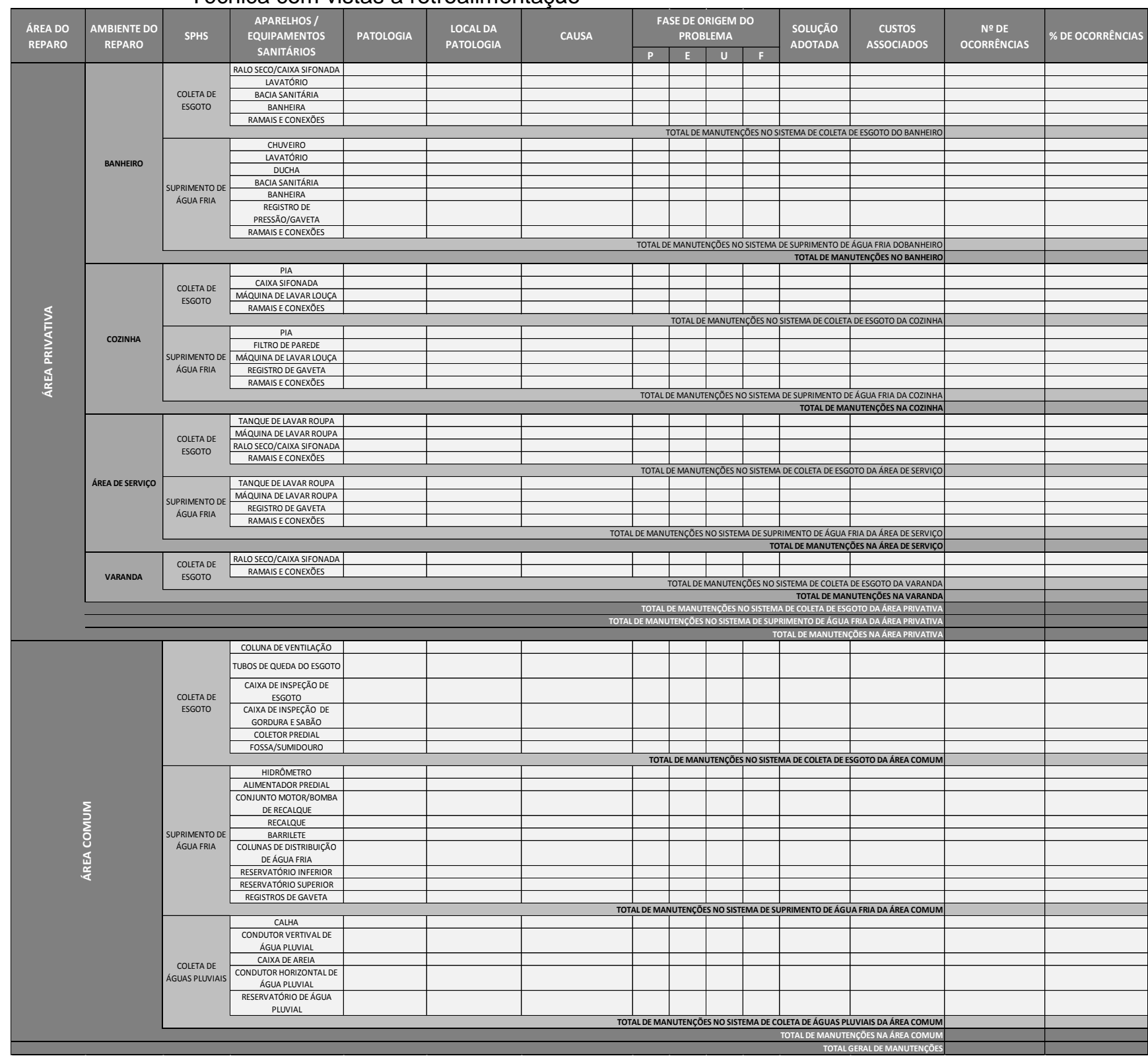

Fonte: autores

7. Após a abertura do registro da reclamação para reparo, a resolução da patologia deve seguir os passos indicados por Gnipper (2010): identificação do problema; identificação das respectivas causas; definição da conduta a ser

Revista Produção Online, Florianópolis, SC, v. 16, n. 4, p. 1285-1308, out./dez. 2016. 
tomada, a qual deve ser acompanhada pelo técnico ou pelo responsável quando necessário; solução propriamente dita do problema e proposta de prevenção ao problema, apontando as possíveis fases do processo que o originaram. Essas informações devem ser registradas em um formulário, que deve ser levado pelo técnico ou operário para o local do reparo;

8. A partir do registro sistematizado das reclamações dos clientes, as empresas podem passar a gerar, periodicamente, relatórios gráficos direcionados à retroalimentação de projetos de SPHS. Podem ser inseridos gráficos de Pareto, a fim de verificar os problemas que mais geram reclamações, com os devidos indicadores de ocorrência de reparos ligados aos SPHS e, por meio de diagrama de Ishikawa, serem mostradas as causas para cada reparo cadastrado no período.

9. Esses relatórios gráficos devem ser apresentados em reuniões técnicas de engenharia. Nessa ocasião devem participar da exposição dos dados de assistência técnica tanto os engenheiros da construtora como também os projetistas envolvidos nos empreendimentos analisados. Conforme indicado pelos próprios projetistas entrevistados nesta pesquisa, o acesso a esses dados deveria acontecer por meio de reuniões periódicas destes projetistas com as empresas contratantes. Assim, além de produzirem os projetos as built, reconhecendo as mudanças feitas ainda em fase de construção, devem também acompanhar a fase de uso de seus projetos.

10. Na ocasião das reuniões do corpo técnico das construtoras, os projetistas podem mostrar suas ideias frente aos problemas, esclarecendo situações que geraram reparos posteriores e propondo mudanças eficazes para os próximos empreendimentos. A ideia é a produção de uma lista de novas diretrizes de projetos, aqui chamadas de alertas de projeto, que pode ser automatizada com recursos de $\mathrm{TI}$, se for o caso.

11. Esses alertas de projeto, portanto, devem ser repassados, por escrito, para a equipe dos escritórios de projeto, de modo a servirem como guia de checagem e validação para a não repetição de problemas ligados aos SPHS.

Considerando o caso exposto na seção 4.3, sobre o caso da caixa de passagem de água pluvial, por exemplo, poderia ser criado um novo alerta de projeto considerando a seguinte diretriz: caixas de passagem devem ser dispostas em zonas de pouca ou nenhuma transição de veículos. Isso poderia de algum modo reduzir problemas daquela natureza.

Após as empresas já terem uma lista considerável de alertas de projeto, essa poderia vir a ser implementada em softwares de checagens de dados, para não tornar o processo enfadonho e cansativo. A partir dos alertas de projetos, podem ser criadas regras para verificação em softwares como o Solibri Model Checker ${ }^{\mathrm{TM}}$, que trabalha a compatibilização de modelos virtuais produzidos em BIM (Buiding Information Modelling) ou mesmo em outros softwares ou repositórios on line de armazenamento de arquivos e dados, como o SADP® (Sistema de Armazenamento 
de Dados de Projetos) ou o Construmanager $\AA$, que, de alguma forma, permitam análises de informações de projetos.

Além disso, se for o caso da existência de um grupo de empresas que trocam informações entre si, como a COOPERCON (Cooperativa de Empresas da Construção) em Fortaleza/Ce, pode haver uma plataforma on line de dados de manutenção, semelhante ao PATORREB do Grupo de Estudos da Patologia da Construção de Portugal. Essa plataforma possui um banco de dados que é de livre acesso na rede mundial de computadores (http://www.patorreb.com) e útil para facilitar o acesso às informações obtidas por meio dos registros patológicos da construção local. Ainda, poderia se fazer um sistema semelhante ao CIS-CAD (Sistema de Informação Coordenado-Desenho assistido por computador), que é utilizado para definir requisitos para uma transferência digital de informação desde a construção de projeto até a operação de construção e compartilhado entre construtores na Dinamarca. Do mesmo modo, poderiam ser conferidas e analisadas patologias cadastradas que foram detectadas a partir do setor assistência técnica de construtoras locais e que geraram alertas de projeto para os SPHS, ou ainda para outros serviços da obra.

\section{CONSIDERAÇÕES FINAIS}

A principal contribuição desta pesquisa foi propor um modelo para retroalimentação de dados do setor de assistência técnica para os projetos de SPHS. Este modelo foi fruto de estudo de campo realizado com três empresas construtoras e três escritórios de projetos SPHS, além da literatura sobre o tema de manutenção e assistência técnica.

Constatou-se que a retroalimentação dos projetos de SPHS ainda não é uma realidade entre as empresas e que as reduções de reparos nessa área, por vezes, são proporcionadas por outros tipos de medidas, como a redução de prazos de garantias, por exemplo, que necessariamente pela existência de aprendizado por meio de feedback. O que acontece é uma possível permanência dos problemas, mas com uma aparente redução do número de reparos. Assim, diminuir os prazos de garantias dos sistemas produzidos pode ser uma perda de oportunidades de melhorias futuras.

De um modo geral, as construtoras aqui estudadas fazem o registro das reclamações dos clientes sobre solicitações de reparos, mas esses registros são mantidos muito mais por razões burocráticas do que por interesse em aprendizado, o que não possibilita grandes análises para melhorias futuras e repasses para os projetistas envolvidos.

Com isso, realizar pesquisas através de banco de dados de reparos normalmente é de difícil execução, a citar a análise inicial desta pesquisa. Isso ocorreu devido à deficiência de uma categorização de dados, ou mesmo de uma nomenclatura mais objetiva dos códigos cadastrados. Assim, propõe-se que os dados registrados no setor de assistência técnica siga uma categorização por 
sistemas construtivos e apresente também os motivadores dos reparos e as soluções tomadas. Além disso, poderiam ainda ser adicionadas fotografias e desenhos aos registros de reparos, explicando quais os principais problemas e comprovando como as melhorias foram bem sucedidas.

Nota-se, portanto, que as empresas precisam de maior gerenciamento em relação à coleta, registro, processamento e análises dos dados obtidos a partir do setor de assistência técnica para que, de fato, possam gerar conhecimento aos outros envolvidos na produção, aos projetistas de SPHS ou até mesmo aos futuros funcionários da empresa que não vivenciaram as experiências passadas. Para esta questão foi proposta uma ferramenta para catalogação das informações.

Por sua vez, os projetistas se mostraram interessados em obter um feedback sobre a qualidade de seus projetos. Neste sentido, o modelo proposto inseriu os escritórios de projeto no contexto do acompanhamento da obra e do uso da edificação integrando-os a todo processo de projeto. Essa integração ente projetistas e construtoras pode aumentar a qualidade do projeto e consequentemente a satisfação dos usuários finais.

Por fim, recomenda-se que o uso de tecnologias da informação para otimizar o uso e compartilhamento destas informações entre empresas e escritórios e até mesmo entre várias empresas do setor. Pesquisas futuras podem imprimir esforço neste sentido: implantação de plataformas de colaboração de dados de assistência técnica tomando como base o modelo proposto nesta pesquisa.

\section{AGRADECIMENTOS}

À CAPES pelo apoio financeiro promovido e ao GERCON - Grupo de Pesquisa e Assessoria em Gerenciamento na Construção Civil, pelo apoio com espaço físico e bolsista.

\section{REFERÊNCIAS}

ALMEIDA, G. G. Avaliação Durante Operação (ADO): metodologia aplicada aos sistemas prediais. 1994. 185 f. Dissertação (Mestrado) - Departamento de Engenharia de Construção Civil, Escola Politécnica da Universidade de São Paulo, São Paulo, 1994.

AMORIM, S. V. Metodologia para estruturação de sistemas de informação para projeto dos sistemas hidráulicos prediais. 1997. 213 f. Tese (Doutorado) - Departamento de Engenharia de Construção Civil, Escola Politécnica da Universidade de São Paulo, São Paulo, 1997.

ARAÚJO, L. S. M. Avaliação durante operação dos sistemas prediais hidráulicos e sanitários em edifícios escolares. 2004. 246 f. Dissertação (Mestrado) - Programa de Pós-Graduação da Faculdade de Engenharia Civil, Arquitetura e Urbanismo, Universidade Estadual de Campinas, Campinas, 2004. 
ARIS, R. B. Maintenance factors in building design. 2006. $112 \mathrm{f}$ Tese (Mestrado) Faculdade de Engenharia Civil, Universidade de Tecnologia da Malásia, Malásia, 2006.

BRITO, J. N. S. Retroalimentação do processo de desenvolvimento de empreendimentos de habitação de interesse social a partir de reclamações de usuários: estudo no programa de arrendamento residencial. 2009. 157 f. Dissertação (Mestrado) - Programa de Pós-Graduação em Engenharia Civil, Universidade Federal do Rio Grande do Sul, Porto Alegre, 2009.

CHONG, W.; LOW, S. Assessment of Defects at Construction and Occupancy Stages. Journal of Performance of Constructed Facilities, v. 19, n. 4, pp. 283-289, nov. 2005. http://dx.doi.org/10.1061/(ASCE)0887-3828(2005)19:4(283)

CONCEIÇÃO, A. P. Estudo da incidência de falhas visando a melhoria da qualidade dos Sistemas Prediais Hidráulicos e Sanitários. 2007. 128 f. Dissertação (Mestrado) Departamento de Engenharia Civil, Universidade Federal de São Carlos, São Carlos, 2007.

CRESWELL, J. W. Projeto de pesquisa: métodos qualitativo, quantitativo e misto.

Tradução de Luciana de Oliveira da Rocha. 2 ed. Porto Alegre: Artmed/Bookman, 2007. pp.184-210.

CUPERTINO, D.; BRANDSTETTER, M. C. G. O. Análise do banco de dados de Assistência Técnica de uma construtora como ferramenta de gestão. In: ENCONTRO NACIONAL DE TECNOLOGIA DO AMBIENTE CONSTRUÍDO, 14, 2012, Juiz de Fora. Anais... Juiz de Fora: ENTAC, 2012. 6p.

FANTINATTI, P. A. P. Ações de gestão do conhecimento na construção civil: evidências a partir da assistência técnica de uma construtora. 2008. 139 f. Dissertação (Mestrado) Programa de Pós-Graduação da Faculdade de Engenharia Civil, Arquitetura e Urbanismo, Universidade Estadual de Campinas, Campinas, 2008. 140

FANTINATTI, P. A. P.; GRANJA, A. D. Captura e reutilização do conhecimento a partir da Assistência Técnica de uma construtora. In: ENCONTRO NACIONAL DE TECNOLOGIA DO AMBIENTE CONSTRUIDO, 11., 2006, Florianópolis. Anais... Florianopolis: ENTAC, 2006. $12 p$.

FONG, P. S. W.; WONG, K. Capturing and reusing building maintenance knowledge: a sociotechnical perspective. In: Knowledge management in the construction: a sociotechnical perspective, cap. 5., pp. 67-89, 2005. Idea Group Publishing.

GNIPPER, S. F. Diretrizes para formulação de método hierarquizado para investigação de patologias em sistemas prediais hidráulicos e sanitários. 2010. 287 f. Dissertação (Mestrado) - Programa de Pós-Graduação da Faculdade de Engenharia Civil, Arquitetura e Urbanismo, Universidade Estadual de Campinas, Campinas, 2010.

GODINHO, M.; MENDES, R.; BARREIROS, J. Informação de retorno e aprendizagem. Horizonte, Lisboa: Livros Horizonte, v.11, n.66, p.217-220, mar./abr. 1995.

HANSEN, A. P; DAMGAARD, T.; HAAS, H. Creating and using FM knowledge in complex building projects. In: Constructions Matter Conference, Copenhagen Business School, Copenhagen, Proceedings... Copenhagen: CBS, 2010.

ILHA, M. S. O; GNIPPER, S. F. A investigação patológica na melhoria dos Sistemas Prediais Hidráulico-Sanitários. Hydro, São Paulo, a. 30, n. 30, p.60-65, abr. 2009. 
JENSEN, P. A. Design integration of facilities management: a challenge of knowledge transfer. Architectural Engineering and Design Management - AEDM, v. 5, n. 3, p.124135, jan. 2009. http://dx.doi.org/10.3763/aedm.2009.0101

JENSEN, P. A. Knowledge transfer from facilities management to building projects: A typology of transfer mechanisms. Architectural Engineering and Design Management AEDM, v. 8, n. 3, p.170-179, ago. 2012. http://dx.doi.org/10.1080/17452007.2012.669131

JOHANSSON, P. Design errors caused by lack of information. In: INTERNATIONAL COUNCIL FOR RESEARCH AND INNOVATION IN BUILDING AND CONSTRUCTION INFORMATION TECHNOLOGY FOR CONSTRUCTION / INFORMATION AND KNOWLEDGE MANAGEMENT IN BUILDING, 28, 2011, Sophia Antipolis. Proceedings... Sophia Antipolis: CIB W78/W102, 2011. 10p.

LÊ, M. A. T; BRØNN, C. Linking experience and learning: Application to multiproject building environments. Engineering, Construction and Architectural Management, v. 14, n. 2, p. 150-163, 2007. http://dx.doi.org/10.1108/09699980710731272

LUNDKVIST, R, MEILING, J. Towards an experience feedback system from building inspections through classification of construction works. In: INTERNATIONAL COUNCIL FOR RESEARCH AND INNOVATION IN BUILDING AND CONSTRUCTION INFORMATION TECHNOLOGY FOR CONSTRUCTION / INFORMATION AND KNOWLEDGE MANAGEMENT IN BUILDING, 28., 2011, Sophia Antipolis. Proceedings... Sophia Antipolis: CIB W78/W102, 2011. 10p.

MENDONÇA, M. C. P.; SALES, A. T. C. Assistência Técnica em uma grande empresa do Estado de Sergipe. In: SIMPÓSIO BRASILEIRO DE GESTÃO E ECONOMIA DA CONSTRUÇÃO, 6., 2009, João Pessoa. Anais... João Pessoa: SIBRAGEC, 2009. 11p.

MÖLLER, E. B.; FRANK, A. G.; CORTIMIGLIA, M. N. Critérios e fatores críticos de sucesso para a implantação de sistemas de informação: um estudo de caso sob a perspectiva de uma empresa implantadora de sistemas. Revista Produção Online, v.14, n. 4, p.13781403, 2014. http://dx.doi.org/10.14488/1676-1901.v14i4.1681

MORGAN, J. M.; LIKER, J. K. Sistema Toyota de desenvolvimento de produto: integrando pessoas, processo e tecnologia. Tradução Raul Rubenich. Porto Alegre: Bookman, 2008. 392p.

PAULA, N.; MOREIRA, F.; ZANFERDINI, A.; NOVAES, C. Identificação da aplicabilidade de conceitos relativos à gestão do processo de projeto em escritórios de projetos de arquitetura e engenharia da cidade de São Carlos/SP. In: ENCONTRO NACIONAL DE TECNOLOGIA DO AMBIENTE CONSTRUÍDO, 12, 2008, Fortaleza. Anais... Fortaleza: ENTAC, 2008. 10p.

RESENDE, M. M.; MELHADO, S. B.; MEDEIROS, J. S. Gestão da Qualidade e Assistência Técnica aos clientes na construção de edifícios. In: CONGRESSO DE ENGENHARIA CIVIL, 5., 2002, Juiz de Fora. Anais... Juiz de Fora. 10p.

SANCHES, I. D. A; FABRICIO, M. M. Projeto para Manutenção. In: WORKSHOP BRASILEIRO DE GESTÃO DO PROCESSO DE PROJETOS NA CONSTRUÇÃO DE EDIFÍCIOS, 8., 2008, São Paulo. Anais... São Paulo: WBGPPCE, 2008. 8p. 
SOUZA, A. M.; SCHMIDT, A. S.; TURCATO, C. R. S. O aprendizado em organizações certificadas pela NBR ISO 9001:2000. Revista Produção Online, v.11, n. 2, p. 289-318, 2011. http://dx.doi.org/10.14488/1676-1901.v11i2.493

SOUZA, R. Metodologia para desenvolvimento e implantação de sistemas de gestão da qualidade em empresas construtoras de pequeno e médio porte. São Paulo, 1997. 46 f. Boletim Técnico de Tese (Doutorado) - Escola Politécnica da Universidade de São Paulo, São Paulo: EPUSP, PCC, 1997.

TZORTZOPOULOS, P. Contribuições para o desenvolvimento de um modelo do processo de projeto de edificações em empresas construtoras incorporadoras de pequeno porte. 1999. 150 f. Dissertação (Mestrado) - Programa de Pós-Graduação em Engenharia Civil, Universidade Federal do Rio Grande do Sul, Porto Alegre, 1999.

ULRICH, K. T.; EPPINGER, S. D. Product design and development. United States of America: The McGraw-Hill Companies, 2 ed., 2000.

YIN, R. K. Estudo de caso: planejamento e métodos. Tradução de Daniel Grassi. 3. ed. Porto Alegre: Bookman, 2005. 212p.

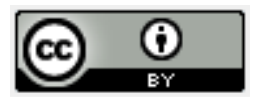

Artigo recebido em 12/01/2016 e aceito para publicação em 09/09/2016

DOI:http://dx.doi.org/ 10.14488/1676-1901.v16i4.2317 